\title{
Avaliação do Atendimento Recebido no CRAS por Famílias Usuárias
}

\author{
Anne Graça de Sousa Andrade \\ Faculdade Luciano Feijão, CE, Brasil.
}

\author{
Normanda Araujo de Morais \\ Universidade de Fortaleza, CE, Brasil.
}

\begin{abstract}
Resumo: A Política Nacional de Assistência Social (PNAS) visa o enfrentamento das desigualdades sociais e preconiza a garantia de direitos de famílias, indivíduos e grupos que deles necessitarem. Neste artigo enfoca-se o Centro de Referência em Assistência Social (CRAS), buscando compreender a avaliação de famílias em situação de vulnerabilidade social acerca do atendimento recebido. A partir da metodologia da Inserção Ecológica foram realizadas entrevistas com seis famílias. A análise de conteúdo das entrevistas evidenciou que as famílias reconhecem a importância do CRAS em suas vidas e na vida da comunidade que habitam, tendendo a descrever mais aspectos positivos (inclusão social, garantia de direitos, bom vínculo beneficiário-profissional, atividades disponibilizadas, desenvolvimento da autonomia e importância do equipamento na comunidade) que os aspectos negativos (precária estrutura física, distância entre o CRAS e suas casas e a alta rotatividade de profissionais). Por fim, sublinha-se a relevância de se escutar os usuários, dando voz aos mesmos.
\end{abstract}

Palavras-chave: Família, CRAS, Avaliação, Aassistência Social, Política Pública.

\section{Assessment, by User Families, of the Service Received in the CRAS}

\begin{abstract}
The National Policy on Social Assistance (PNAS) aims at tackling social inequalities and calls for the guarantee of rigths to families, individuals and groups that need them. This article focuses on the Reference Center of Social Assistance (CRAS) and seeks to understand the assessment that socially vulnerable families make of the service they receive in this facility. Interviews with six families were held using the methodology of Ecological Insertion. Content analysis of interviews showed that the families recognize the importance CRAS has in their lives and in the life of the community they inhabit, and tend to describe more positive aspects (social inclusion, guarantee of rights, good beneficiary-professional bond, available activities, development of autonomy and importance of service facilities to the community) than negative ones (precarious physical structure, distance between CRAS and their homes and the high turnover of professionals). Finally, the relevance of hearing the users, giving voice to them, was highlighted.
\end{abstract}

Keywords: Family, CRAS, Evaluation, Social Assistance, Public Policy. 


\title{
Evaluación de la Atención Recibida en el CRAS por Familias Usuarias
}

\begin{abstract}
Resumen: La Política Nacional de Asistencia Social (PNAS) tiene como objetivo enfrentar las desigualdades sociales y propone que se garanticen los derechos de las familias, individuos y grupos que necesiten de sus servicios. Este artículo se enfoca en el Centro de Referencia en Asistencia Social (CRAS), con el fin de comprender la evaluación que familias en situación de vulnerabilidad social hacen de la atención recibida. A partir de la metodología de Inserción Ecológica fueron realizadas entrevistas con seis familias. El análisis de contenido de las entrevistas reveló que las familias reconocen la importancia del CRAS en sus vidas y en la de la comunidad que habitan, y tienden a describir más aspectos positivos (inclusión social, garantía de sus derechos, buen vínculo beneficiario-profesional, actividades proporcionadas, desarrollo de la autonomía, e importancia del equipo en la comunidad), que negativos (estructura física precaria, distancia entre el CRAS y sus casas y alta rotación de profesionales). Finalmente, se subraya la relevancia de escuchar a las personas atendidas, otorgándoles voz propia.
\end{abstract}

Palabras clave: Familia, CRAS, Evaluación, Assistencia Social, Política Pública.

\section{Introdução}

A assistência social no Brasil, efetivada como política pública e direito do cidadão é um fenômeno recente e possui como marcos legais a Constituição Federal de 1988, a regulamentação da Lei Orgânica da Assistência Social (LOAS) no ano de 1993 e a aprovação da Política Nacional de Assistência Social (PNAS) em 2004. A política de assistência social está inserida no sistema do bem-estar social brasileiro, juntamente como a previdência social e o direito à saúde; e juntas compõem o chamado tripé da seguridade social no Brasil. De acordo com a PNAS (Brasil, 2004), a assistência social deverá ser prestada a quem dela necessitar, independentemente de contribuição à seguridade social. Além disso, dentre seus objetivos estão a proteção à família, à maternidade, à infância, à adolescência e à velhice.

A assistência social no Brasil organiza-se em Proteção Social Básica (PSB) e Proteção Social Especial (PSE) que se distinguem pelo oferecimento de programas, serviços, ações e benefícios. De caráter preventivo, a PSB visa evitar o agravamento das vulnerabilidades e riscos sociais, envidando esforços para que não ocorra violação dos direitos de cidadania e se fortaleçam os vínculos familiares e comunitários. Os serviços e ações da PSB são oferecidos prioritariamente no Centro de Referência de Assistência Social (CRAS), unidade pública estatal de base territorial, que se localiza, em geral, em áreas de maior vulnerabilidade social. A PSE tem por objetivo oferecer serviços, programas, ações e benefícios de caráter protetivo, quando há iminência ou já ocorreu a violação de direitos, a fim de se resgatar a dignidade e as condições de vida das famílias ou indivíduos. Nesse sentido, a PNAS operacionaliza a proteção social no Brasil estabelecendo a divisão de responsabilidades e competências entre as esferas de governo, níveis e instrumentos de gestão, critérios de partilha e transferência de recursos, proteções a serem ofertadas, entre outros aspectos, que possibilitam a implementação do Sistema Único de Assistência Social (SUAS).

O foco do presente artigo é a PSB, especificamente o CRAS, equipamento considerado a "porta de entrada" desse novo modelo de assistência social. A partir da práxis anterior da primeira autora como psicóloga comunitária em um CRAS de um município no interior do estado do Ceará, bem como a partir das reflexões e questionamentos acerca do atendimento disponibilizado às famílias beneficiárias, pretendeu-se dar visibilidade à subjetividade das famílias atendidas, a fim de que elas próprias avaliem os atendimentos que recebiam.

O interesse pelas famílias usuárias decorre do fato de que a nova política de assistência social no Brasil coloca a família em lugar de destaque e considera três vertentes: "as pessoas, as suas circunstâncias e dentre elas seu núcleo de apoio primeiro, isto é, a família" (Brasil, 2004, p. 15). Nesse sentido, os atendimentos às famílias devem ser realizados de forma processual e primando a centralidade sociofamiliar, de forma que as famílias passam a ser vistas como possuidoras de características peculiares e como ativas em seu processo de desenvolvimento, e não como um "alvo" de uma ação 
ou instrumento para alcance de resultados, como acontece em diversos casos de elaboração e execução de políticas públicas. Essa mudança epistemológica de concepção de família na atualidade é acompanhada pela PNAS que, a partir de transformações estruturais, passou a conceber a família de forma ampliada "como núcleo afetivo, vinculado por laços consanguíneos, de aliança ou afinidade" (Brasil, 2004, p. 90).

No tocante à produção acadêmica sobre a assistência social e sua articulação com a temática de família, verifica-se que ainda é bastante incipiente, demandando maior atenção de pesquisadores e profissionais inseridos nesse contexto. As produções tendem a centralizar-se na atuação dos psicólogos nos CRAS/SUAS (Andrade, \& Romagnolis, 2010; Bastos, Gondim, \& Borges-Andrade, 2010; Leão, Oliveira, \& Carvalho, 2014; Macedo et al., 2011; Macedo, \& Dimenstein, 2012; Oliveira, Dantas, Solon, \& Amorim, 2011; Senra, \& Guzzo, 2012; Silva, \& Corgozinho, 2011; Tavares, 2014); na inserção da Psicologia Comunitária no SUAS (Nepomuceno, Ximenes, Cidade, Mendonça, \& Soares, 2008; Ximenes, Paula, \& Barros, 2009) ou na perspectiva de um dos membros da família (quase sempre mulheres) sobre um determinado assunto, como o Bolsa Família, por exemplo (Paula, 2010; Perez, 2009). Tal fato, por sua vez, sugere uma incongruência entre o trabalho social que pressupõe a PNAS - que possui a família como ponto central das intervenções - e as produções acadêmicas atuais sobre o tema. Além disso, comprova a importância de se valorizar e pesquisar a avaliação que as famílias usuárias têm sobre o atendimento recebido nos CRAS.

\section{A Psicologia na assistência social: "para além das paredes dos consultórios"}

A partir dos anos 1990, concomitantemente às mudanças ocorridas no campo da saúde e da assistência social, que desencadearam na formulação do Sistema Único de Saúde (SUS) e do SUAS, a Psicologia expandiu significativamente seu espaço de atuação, construindo uma nova práxis voltada à populações antes negligenciadas, como é o caso de pessoas em situação de vulnerabilidade e risco social.

As inúmeras demandas sociais que explodiam no cenário nacional (seca, pobreza, violência, dentre outros) e as ofertas de trabalho para os psicólogos nas políticas públicas colocavam em xeque uma forma tradicional e hegemônica de atuação. Nesse sentido, marcas epistemológicas tradicionais do campo "psi", as quais estavam incrustadas nas práticas profissio- nais começaram a ser questionadas. Dentre elas, destacam-se: a naturalização do fenômeno psicológico, resultando em uma concepção de universalidade do fenômeno psíquico, o que distancia a Psicologia da realidade social; o deslocamento da prática profissional dos interesses sociais e das disputas políticas da sociedade; e a responsabilização das pessoas como únicas responsáveis pelo seu desenvolvimento, descartando o papel da sociedade e compreendendo o fenômeno psicológico a partir do próprio homem (Bock, 2003).

A construção de uma "nova Psicologia" teve início desde a década de 1970, período em que os psicólogos começaram a perceber a saturação do mercado de trabalho e as dificuldades metodológicas de atuação em contexto de desigualdades, como a que o Brasil e América Latina se encontravam (Yamamoto, 2007; Yamamoto, \& Oliveira, 2010). Em contrapartida, a construção de novas políticas públicas se caracterizava como um desafio, pois os psicólogos não estavam preparados academicamente para atuar nesse campo.

A partir de vários movimentos político-sociais, como a ditadura e a redemocratização do Brasil, os psicólogos começaram a refletir e criticar o fazer profissional até então hegemônico. A conjuntura política, econômica e social propícia a esses questionamentos, bem como a significativa miséria que parte da população brasileira se encontrava, proporcionou a esses profissionais um desvio da prática profissional tradicional para a atuação em novos espaços, especificamente nos "campos de bem-estar social de cunho preventivo e compensatório" (Yamamoto, 2003, p. 41).

Foinesse cenário de deselitização daPsicologia, de preocupação com as questões sociais e com as formas de relações de desigualdades, que consequentemente davam margem ao autoritarismo (Amoretti, Cruz, \& Freitas, 2010), que muitos psicólogos iniciaram (e iniciam) suas carreiras. Se por um lado a oferta de emprego nesse campo estava cada vez mais crescente, por outro, esses profissionais sentiram a necessidade de colaborar para uma sociedade mais justa e igualitária. Preocupados com tamanha miséria, começaram a delimitar novos âmbitos de atividades, saindo das escolas, consultórios e empresas, e se dirigindo para as comunidades, favelas, associações de moradores, Organizações Não Governamentais (ONG) etc. $\mathrm{O}$ intuito foi ampliar o acesso ao mercado de trabalho e defender uma Psicologia menos academicista, menos intelectual e mais ligada às questões do povo (Freitas, 1998). 
Especificamente no CRAS, cerca de 9.507 psicólogos estão em atuação, totalizando $23,3 \%$ da quantidade de trabalhadores da assistência social no Brasil (Brasil, 2015). Constata-se, então, uma mudança de perfil dos psicólogos brasileiros na atualidade. De acordo com Seixas (2009), a atuação do psicólogo nas políticas públicas passou de área emergente para mainstream da profissão, dado o significativo mercado de trabalho que tem se constituído para psicólogos, especialmente os recém-formados. Em pesquisa realizada no Rio Grande do Norte, o autor aplicou questionários com o intuito de traçar um perfil dos psicólogos que atuam no estado. De 294 profissionais que responderam ao questionário, 121 trabalhavam com políticas sociais, sendo $32,1 \%$ em instituições de assistência social, 32,1\% em instituições de saúde coletiva e $13,75 \%$ em ONGs, totalizando quase metade dos profissionais atuando com os setores menos privilegiados da população. Essa realidade não se difere da de outros estados brasileiros.

O psicólogo como trabalhador da assistência social tem "como finalidade básica o fortalecimento dos usuários como sujeitos de direitos e o fortalecimento das políticas públicas" (Centro de Referência Técnica em Psicologia e Políticas Públicas, 2007, p. 17), além de atuar no sentido de levar em conta a dimensão subjetiva dos indivíduos, favorece o desenvolvimento da autonomia e cidadania. Ainda, segundo o manual, "as práticas psicológicas não devem categorizar, patologizar e objetificar as pessoas atendidas" (p. 16), ou seja, deve-se ter bastante cuidado para não apenas trazer o consultório para a comunidade, e sim trabalhar no sentido do desenvolvimento de uma clínica ampliada, rompendo paradigmas e deflagrando processos de subjetivação, além de promover a interdisciplinaridade (Benevides, 2005; Guerra, 2002).

A respeito da avaliação que as famílias usuárias fazem do atendimento recebido no CRAS, deve-se dar especial destaque à relação entre as famílias beneficiárias e os trabalhadores da assistência social que atuam nesses equipamentos. Nesse sentido, espera-se que os profissionais primem pela promoção e fortalecimento dos vínculos socioafetivos e pela emancipação social das famílias e seus membros (CREPOP, 2007). Na relação com as famílias, que é o principal alvo de intervenções proposto pela PNAS, o Conselho Federal de Psicologia (CFP) chama a atenção para o processo de "culpabilização" delas. Tendo em vista o reconhecimento da família como sujeito de direitos e sua supervalorização, na área da proteção social, faz-se necessária a ponderação sobre a responsabilização da família, tanto no que tange ao "sucesso" ou "fracasso" desse sistema e de seus membros. No entanto, verifica-se que os estudos tendem a se concentrar na prática do profissional inserido nas políticas públicas, sendo que as famílias nesse contexto ainda são pouco pesquisadas.

Para uma prática em territórios antes desconhecidos, faz-se necessário um embasamento teórico-metodológico para esse novo modo de ser trabalhador. Estudos revelam a impotência do profissional recém-formado que é absorvido por esse novo mercado (Andrade, \& Romagnoli, 2010; Leão et al., 2014; Macedo, \& Dimenstein, 2012). Em virtude das dúvidas quanto às suas reais atividades e sua interface com as demandas sociais, os psicólogos estão sujeitos a exercer insatisfatoriamente o atendimento psicossocial, que, por vezes, é confundido com a clínica tradicional (Oliveira et al., 2011).

Além do despreparo acadêmico, outros desafios são citados, como a precarização do serviço público (Antunes, 2005; Bastos et al., 2010; Senra, 2009) e a desvalorização da categoria profissional com baixos salários, alta rotatividade e escassez de concursos públicos (Barros, 2007; Macedo, 2007; Macedo et al., 2011; Oliveira et al., 2011; Raichelis, 2010; Ximenes et al., 2009). Esses desafios contribuem para uma prática, de todos os profissionais da assistência social, destoante do que rege a PNAS. A indefinição de contratos de trabalho, que são muitas vezes temporários, desmotiva os profissionais e dificultam o desenvolvimento de intervenções contínuas. Dessa forma, reitera-se que preparo acadêmico, capacitação continuada, maiores investimentos no setor público e fortalecimento dos recursos humanos são fatores imprescindíveis na implementação e execução da "verdadeira" política de assistência social.

\section{A família na PNAS: "foco na família ou a família em foco?"}

No estudo de famílias socialmente vulnerabilizadas, que são os beneficiários da política de assistência social, deve ser considerada a concepção de família adotada pela própria política e pelos profissionais que nela atuam. Em pesquisa realizada por Santos (2010) sobre a percepção de família dos assistentes sociais dos CRAS e CREAS de São Paulo foram identificados relatos desses profissionais referentes à família, como: agrupamentos formados por 
um dos pais e seus filhos, bem como aqueles sistemas constituídos por pais e mães em segundas uniões conjugais, cujos filhos coabitam, formando um sistema fraterno, cujos laços são afetivos e não consanguíneos. Emergiu, ainda, a noção de que se pode considerar família um conjunto de indivíduos que têm entre si uma história própria e laços culturais, afetivos e de proteção. Tal concepção corrobora o que estabelece a PNAS (Brasil, 2004), que considera a família para além dos laços consanguíneos.

Um dos princípios norteadores da PNAS é a "centralidade familiar", que identifica a família como o ponto de maior relevância do trabalho social. Sposati (2009) conceitua centralidade familiar como sendo a forma de trabalho que coloca a família como principal agente de socialização primária e lócus privilegiado para o desenvolvimento da cidadania, da proteção e do cuidado com seus membros. Percebe-se nessa discussão que o foco do trabalho da PNAS e do SUAS é a família e traz em sua base, a concepção de que todas as outras necessidades e públicos da assistência social estão, de alguma maneira, vinculados a ela, quer seja no momento de utilização dos programas, projetos e serviços, quer seja no início do ciclo de vulnerabilização e violação de direitos que gera a necessidade do indivíduo vir a ser alvo da atenção da referida política (Brasil, 2005). Entretanto, o documento não deixa claro que cada família possui suas peculiaridades, que estas devem ser levadas em consideração, remetendo à noção (equivocada) de que as ações podem ser realizadas de forma generalizada.

Considerando a família como núcleo social básico de acolhida, convívio, autonomia, sustentabilidade e protagonismo social (Brasil, 2004) e o eixo estruturante da gestão do SUAS que prioriza a "matricialidade sociofamiliar”, é possível estabelecer uma nova concepção acerca do trabalho destinado a esse público. A matricialidade sociofamiliar sugere um trabalho junto à família como possibilidade de atuação integral e não fragmentada. Para Sposati (2009), a matricialidade sociofamiliar preconiza as famílias com suas necessidades e peculiaridades, entendendo-as como sujeito coletivo. Pensar a matricialidade sociofamiliar significa compreender qual família o profissional está atendendo e o momento e situação social em que ela se encontra, com a perspectiva de gerir tais aspectos e ações a partir de suas especificidades, considerando as suas vontades.

Afonso, Hennon, Carico, e Peterson (2013) discutem as metodologias de trabalho e intervenções sociais com famílias vulneráveis no SUAS, afirmando que tais estratégias devem ser embasadas em uma visão emancipadora, democrática, participativa e dialógica em prol do acesso aos direitos e cidadania. Os autores fazem referência a alguns pontos que devem ser levados em conta no trabalho com famílias, tais como: a participação das famílias nas decisões e projetos; desenvolvimento de habilidades sociais dos indivíduos e das famílias; fortalecimento da comunidade, grupos, famílias e rede de apoio; e associação para o desenvolvimento de projetos locais e trabalhos em grupo.

Considerando-se, portanto, as diretrizes da PNAS, bem como o reconhecimento da autonomia das famílias, sua liberdade de escolha, seu movimento, diversidade e principalmente a importância de escutá-las, esse artigo se propõe a dar-lhes voz e a compreender como elas avaliam o atendimento recebido no CRAS. Pretende-se, assim, com esse estudo contribuir para a implementação e melhoria das ações desenvolvidas pelas políticas públicas para famílias em vulnerabilidade social, uma vez que as falas das famílias poderão ajudar a nortear o trabalho dos profissionais e gestores.

\section{Método}

Trata-se de um estudo qualitativo, exploratório e descritivo. Com o intuito de compreender a forma como as famílias que são acompanhadas pelo CRAS avaliam o atendimento a elas disponibilizado, optou-se pelo uso metodologia da Inserção Ecológica (Cecconello, \& Koller, 2003; Prati, Couto, Moura, Poletto, \& Koller, 2008) para a coleta dos dados.

A Inserção Ecológica está baseada na Abordagem Bioecológica do Desenvolvimento Humano de Urie Bronfenbrenner (1989). Tal metodologia de pesquisa se mostra como uma forma privilegiada e com validade ecológica para estudos com famílias, pois pressupõe a bidirecionalidade que a pessoa $\mathrm{e}$ o ambiente têm de se autoinfluenciar e permite ao pesquisador entrar em contato mais sistemático e duradouro com os participantes da pesquisa, além de garantir uma maior vinculação e qualidade dos dados.

\section{Participantes}

Participaram desse estudo seis famílias denominadas ficticiamente de família Abreu, Bastos, Castro, Duarte, Esteves e Fagundes. As famílias foram selecionadas a partir da colaboração da equipe técnica de um 
CRAS de um município no interior do Nordeste brasileiro, com população de aproximadamente 200.000 habitantes. Por meio da técnica de brainstorming, solicitou-se que a equipe do CRAS (composta de dois assistentes sociais, um psicólogo, um pedagogo e quatro educadores) indicasse o nome de 10 famílias que consideravam de alta adesão e 10 famílias que consideravam de baixa adesão. Considerou-se como famílias de alta adesão aquelas famílias que participavam das atividades propostas pelo CRAS, que cumpriam os encaminhamentos sugeridos e que se interessavam pela superação da vulnerabilidade social; já as de baixa adesão eram aquelas que não se implicavam nesse processo. A equipe conseguiu listar os nomes de 10 famílias de alta adesão e oito famílias de baixa adesão. Em seguida, foram sorteados três famílias de cada grupo, a fim de contemplar diferentes percepções sobre $o$ atendimento recebido no CRAS.

Conforme mostra a Tabela 1, três famílias apresentavam uma configuração nuclear e três podem ser classificadas como monoparentais feminina. A renda média familiar variou de $\mathrm{R} \$ 200,00$ a $\mathrm{R} \$ 1.500,00$ e o nível de escolaridade dos responsáveis era bastante baixo, variando de analfabeto ao $5^{\circ}$ ano do Ensino Fundamental. Mais detalhes acerca da caracterização das famílias participantes são descritas na seção de Resultados

Tabela 1

Caracterização das famílias entrevistadas.

\begin{tabular}{|c|c|c|c|c|c|c|c|}
\hline Família & Adesão & $\begin{array}{l}\text { Configuração } \\
\text { familiar }\end{array}$ & $\begin{array}{c}\text { Renda } \\
(\mathrm{R} \$)\end{array}$ & $\begin{array}{l}\text { Rede de } \\
\text { apoio }\end{array}$ & Componentes & $\begin{array}{l}\text { Idade } \\
\text { (anos) }\end{array}$ & Escolaridade \\
\hline \multirow{4}{*}{ Abreu } & \multirow{4}{*}{ Baixa } & \multirow{4}{*}{$\begin{array}{l}\text { Monoparental } \\
\text { feminina }\end{array}$} & \multirow{4}{*}{812} & \multirow{4}{*}{$\begin{array}{l}\text { Posto de } \\
\text { Saúde }\end{array}$} & Avô & 71 & Analfabeto \\
\hline & & & & & Mãe & 30 & Até $5^{\circ}$ ano \\
\hline & & & & & Filha 1 & 14 & $9^{o}$ ano \\
\hline & & & & & Filha 2 & 6 & $1^{\circ}$ ano \\
\hline \multirow{6}{*}{ Bastos } & \multirow{6}{*}{ Baixa } & \multirow{6}{*}{ Nuclear } & \multirow{6}{*}{500} & \multirow{6}{*}{ Sem vínculo } & Pai & 30 & Até $8^{\circ}$ ano \\
\hline & & & & & Mãe & 27 & Até $3^{\circ}$ ano \\
\hline & & & & & Filha 1 & 10 & $4^{\circ}$ ano \\
\hline & & & & & Filha 2 & 7 & $5^{\circ}$ ano \\
\hline & & & & & Filho 1 & 12 & $7^{\circ}$ ano \\
\hline & & & & & Filho 2 & 5 & Infantil I \\
\hline \multirow{4}{*}{ Castro } & \multirow{4}{*}{ Baixa } & \multirow{4}{*}{ Nuclear } & \multirow{4}{*}{$1.500,00$} & \multirow{4}{*}{ ONG } & Pai & 64 & Semianalfabeto \\
\hline & & & & & Mãe & 52 & Até $3^{\circ}$ ano \\
\hline & & & & & Filha & 22 & $2^{\circ}$ ano \\
\hline & & & & & Filho & 29 & APAE \\
\hline \multirow{3}{*}{ Duarte } & \multirow{3}{*}{ Alta } & \multirow{3}{*}{$\begin{array}{l}\text { Monoparental } \\
\text { feminina }\end{array}$} & \multirow{3}{*}{200} & \multirow{3}{*}{ Sem vínculo } & Mãe & 38 & Semianalfabeta \\
\hline & & & & & Filha & 14 & $9^{\circ}$ ano \\
\hline & & & & & Filho & 16 & $2^{\circ}$ ano \\
\hline \multirow{5}{*}{ Esteves } & \multirow{5}{*}{ Alta } & \multirow{5}{*}{ Nuclear } & \multirow{5}{*}{800} & \multirow{5}{*}{ Igreja } & Pai & 44 & Analfabeto \\
\hline & & & & & Mãe & 39 & Analfabeta \\
\hline & & & & & Filha & 18 & Até $5^{\circ}$ ano \\
\hline & & & & & Filho & 15 & $8^{\circ}$ ano \\
\hline & & & & & Neta & 1 & Não estuda \\
\hline \multirow{4}{*}{ Fagundes } & \multirow{4}{*}{ Alta } & \multirow{4}{*}{$\begin{array}{l}\text { Monoparental } \\
\text { feminina }\end{array}$} & \multirow{4}{*}{280} & \multirow{4}{*}{ Igreja } & Mãe & 47 & Analfabeta \\
\hline & & & & & Filha & 15 & $1^{\circ}$ ano \\
\hline & & & & & Filho 1 & 18 & $9^{\circ}$ ano \\
\hline & & & & & Filho 2 & 12 & $7^{\circ}$ ano \\
\hline
\end{tabular}




\section{Instrumentos}

Os instrumentos utilizados nessa pesquisa foram: questionário sociodemográfico, entrevista estruturada do grupo familiar e diário de campo. O questionário sociodemográfico teve o intuito de conhecer o perfil das famílias estudadas. Era composto por 10 questões relacionadas à composição familiar, ocupação, serviço do CRAS acessado pela família, questões econômicas (renda e benefícios recebidos), moradia e apoio da rede socioassistencial.

A entrevista estruturada do grupo familiar era composta de 20 questões e foi elaborada para esse estudo pelas autoras desse artigo. Tinha como proposta descrever como cada membro da família percebia o atendimento disponibilizado pelo CRAS em âmbito individual e grupal e como os atendimentos influenciavam a dinâmica familiar.

Por último, utilizou-se o Diário de Campo para o registro das ações e percepções da pesquisadora no decorrer do processo de pesquisa, enriquecendo os dados coletados, com observações sobre as famílias (no CRAS e em suas casas). O uso do diário de campo serviu, sobretudo, para facilitar a análise dos dados, descrevendo fielmente percepções e sentimentos vivenciados pelos pesquisadores durante todo o processo de pesquisa (Morais, Koller, \& Raffaelli, 2016).

\section{Procedimentos}

Essa pesquisa está pautada na Resolução $\mathrm{n}^{\circ} 466 / 2012$, do Conselho Nacional de Saúde, que dispõe sobre as diretrizes que regulamentam as pesquisas envolvendo seres humanos e obteve a aprovação do Comitê de Ética da universidade de origem das autoras (Processo no 20979813.2.0000.5052).

Após a indicação das famílias pela equipe do CRAS, foram realizadas visitas nas casas das famílias, como parte da inserção ecológica e negociado o melhor horário para a realização da entrevista grupal, solicitando que a maior parte dos membros estivesse presente. Em todas as famílias não houve problemas quanto a esta negociação, e as famílias cumpriram o acordado, sendo sempre muito solícitas. Em seguida, foi solicitado o preenchimento do Termo de Consentimento Livre e Esclarecido (TCLE) pelos diferentes membros da família e iniciou-se a fase da coleta de dados, no horário combinado e escolhido por elas. Em alguns casos, não foi possível entrevistar o grupo familiar como todo, pois os membros que marcaram de participar não cumpriram o compromisso ou decidiram não mais participar da entrevista no decorrer da mesma, como o pai da família Castro ao ser perguntado sobre a efetividade dos serviços: "olhe, eu não sei não, eu vou ter que sair agora, mas tudo de bom pra senhora. Vou deixar aí a mulher pra responder essas suas perguntas".

Concernente ao que Prati et al. (2008) propõem sobre a importância de considerar alguns aspectos para a realização da Inserção Ecológica com validade, a presente pesquisa utilizou-se de diário de campo para relatar o acompanhamento das famílias nos atendimentos (grupais e individuais) no CRAS; promoveu-se a vinculação com a instituição, através de visitas constantes ao órgão; e buscou-se a vinculação com as famílias específicas que participaram do estudo, por meio de visitas para realização das entrevistas e conversas formais e informais na própria casa das famílias por um período de quatro meses, totalizando dezoito visitas. Considera-se que um grande diferencial da inserção da pesquisadora (primeira autora desse artigo) nesse contexto, foi a sua inserção prévia/anterior como psicóloga do referido CRAS (julho/2008 a julho/2012), o que garantia o conhecimento da realidade daquela comunidade onde o CRAS estava localizado e mesmo de algumas famílias participantes do estudo.

No que se refere à análise de dados, optou-se pelo procedimento da análise temática de conteúdo (Bardin, 1979). Esta consistiu na leitura exaustiva das entrevistas, no estabelecimento de aspectos comuns e diferentes entre as respostas dos participantes e, finalmente, no levantamento de uma grande categoria temática, a saber: aspectos positivos e negativos do atendimento oferecido pelo CRAS.

\section{Resultados e Discussão}

\section{Aspectos positivos e negativos do atendimento}

A análise das entrevistas demonstrou que os aspectos positivos se sobressaíram na avaliação do atendimento recebido pelas famílias usuárias no CRAS, independentemente da família ser de baixa ou alta adesão: "De bom é quase sempre, eu não me lembro de nenhuma vez que eu fui maltratada lá não” (Mãe, Família Esteves)

As famílias entrevistadas não conseguiram descrever e avaliar separadamente cada tipo de atendimento aos quais estão inseridas, impossibilitando uma análise detalhada de cada serviço proposto na PNAS na PSB e que estavam ativos no CRAS durante a coleta de dados, são eles: Atendimento/acompanhamento do Programa 
Bolsa Família (PBF); Serviço de convivência e fortalecimento de vínculos de seis a 15 anos; Projovem Adolescente; Grupo de idosos e grupos de inclusão produtiva em parceria com o Programa Nacional de Acesso ao Ensino Técnico e Emprego (Pronatec). Entretanto, foi possível perceber, durante a inserção ecológica, uma percepção positiva do CRAS e o quanto essa instituição é importante para aquelas famílias e comunidade. A mãe da família Fagundes relata que o acompanhamento do CRAS e CREAS salvou a sua vida e a vida da sua família:

Eu vivia em uma vida muito ruim, era muita violência, meu marido chegava aqui, mantinha relações sexuais comigo à força, eu acho que era tipo um estupro, meus meninos vendo tudo, era um inferno. Mas aí quando eu descobri que tinha gente que podia me ajudar, as meninas lá do CRAS e do CREAS. Eu acreditei que podia sair dessa vida, eu tive coragem, e elas me ajudaram muito. Eu acho que se não fosse elas eu acho que hoje eu estava morta, ou ele tinha me matado, ou eu tinha me matado! (Mãe, Família Fagundes).

Dentre esses aspectos positivos está principalmente a boa relação que têm com os profissionais, de se sentirem bem sendo escutadas por eles:

Apesar de não frequentar direto o CRAS, quando vou lá as pessoas sempre me tratam bem, do guarda [vigia] às assistentes sociais... aquelas meninas gostam muito da minha filha, sempre convidam elas para as coisas que tem lá (Mãe, Família Castro).

Durante os encontros, as crianças conversavam, brincavam, sorriam e interagiam com a pesquisadora. Nesse sentido, o desenvolvimento desses processos proximais $^{1}$ foi valoroso para a dessensibilização e elaboração de uma relação de confiança entre a entrevistadora e famílias entrevistadas, o que auxiliou a aplicação dos instrumentos (questionário sociodemográfico e entrevista estruturada). Das quatro famílias com crianças, apenas uma tinha os filhos participando atualmente de atividades no CRAS e estes demonstraram afetividade pelas atividades e conhecimento da proposta do CRAS: "Ah, lá a gente brinca, pinta, participa do Serviço de Convivência e Fortalecimento de Vínculos, as 'tias' são boas, elas ensinam muito a gente" (Filha 1, Família Bastos).

No que tange à questão assistencialista, ranço histórico da assistência social no Brasil, as crianças e as adolescentes expuseram um olhar diferente dos adultos, focando principalmente na necessidade de uma excelência dos serviços prestados e em nenhum momento falaram sobre a questão de doação (alimentos, roupas, benefícios monetários etc.) que os adultos trouxeram: "Lá é pra dar um colchão, assim no caso do pai, um colchão d'agua, uma cadeira de roda, um remédio... ajudar os pobres" (Mãe, Família Abreu).

Em contraponto, a fala de uma adolescente: "O que eu tenho mais vontade de fazer são cursos, pra arranjar logo um emprego, eu acho que no CRAS não tem essas coisas não, mas se tivesse eu ia fazer!" (Filha 1, Família Abreu).

Uma possível justificativa para $\mathrm{o}$ fato das crianças/adolescentes terem citado outros aspectos na perspectiva de um atendimento voltado à garantia de direitos sociais, quando comparados aos participantes adultos pode estar relacionada aos fatores listados a seguir: 1) essas crianças e adolescentes são os que mais frequentam o CRAS, pois eles estão diariamente nos serviços de convivência. Dessa forma, por estarem em contato direto com a PNAS, poderiam entender melhor ao que ela se propõe, enquanto que as mães/pais só comparecem ao CRAS esporadicamente e por esse motivo tendem a entender a política de assistência social de forma distorcida; 2) existe uma grande influência da cultura assistencialista no Brasil. Assim sendo, como os adultos vivenciaram historicamente ações de benemerência, com as da Legião da Boa Vontade (LBV) antes da Constituição de 1988, é possível que ainda estejam impregnados, mesmo que inconscientemente, com essa dimensão em suas vidas; 3 ) as crianças e adolescentes estão sendo trabalhados há algum tempo e essa percepção diferenciada pode ser fruto das intervenções do CRAS, que buscam promover protagonismo, emancipação, formação de cidadãs, convívio grupal e desenvolvimento de potencialidades, por meio do trabalho dos educadores sociais e acompanhamento técnico, o que sugere que o trabalho está tendo êxito.

\footnotetext{
${ }^{1}$ Os processos proximais caracterizam-se pelo estabelecimento de uma interação recíproca, progressivamente mais complexa, entre um organismo humano e as pessoas/objetos do seu ambiente imediato, em que ambas as partes se mantém ativas e se estimulam mutuamente (Bronfenbrenner, 1995).
} 
Outra concepção positiva sobre os atendimentos está relacionada às contribuições que o CRAS trouxe às dinâmicas internas de cada família. Estas tenderam a ressaltar as orientações da equipe destinadas aos adolescentes, a mudança de comportamento dos mesmos depois que passaram a participar dos grupos e a melhora na convivência familiar.

Assim, se o Mário [filho 1] não tivesse entrado nessas amizades, ele frequentava bem direitinho o Projovem. Ele, quando frequentava, se comportava bem, pelo menos aqui dentro de casa, ele nunca foi mal criado, não, também nunca roubou nada pra trocar por droga, não. O negócio foi essas amizades aí mesmo. Eu dava graças a Deus que ele ia pro Projovem, ele chegava aqui alegre contando as coisas que fez lá (Mãe, Família Duarte).

Em contrapartida, o fator distância e a rotatividade de profissionais foram os mais citados como aspectos negativos, reclamações bastante escutadas por quem trabalha no campo da assistência social. A distância entre casas das famílias e o CRAS compromete significativamente a cobertura do território, a ida dos técnicos até as residências, para realizar as visitas domiciliares e a presença dos beneficiários no CRAS, pois, além de o acesso ser difícil, a falta de transporte é outro empecilho por elas enfrentado. Esse aspecto foi exposto explicitamente por duas famílias (Castro e Duarte), porém todas as famílias afirmam que isso é maléfico para elas e para o serviço, pois além da distância territorial, o fator violência, causada principalmente por briga de gangs dificulta o seu deslocamento.

Era muito bom, eu adorava ir para o Projovem, mas, depois que mudou lá pra baixo, a mãe não deixa eu ir mais não, porque tem muito "mala" por ali, teve até umas amigas que foram assaltadas, se fosse aqui mais perto eu ia todo dia (Filha, Família Castro).

Uma das alternativas propostas para o CRAS ficar mais perto dessas famílias que moram em bairros mais distantes é a retomada do processo de descentralização com a composição de uma equipe volante. Segundo o MDS (Brasil, 2014), a equipe volante consiste em uma equipe adicional que integra um CRAS em funcionamento e objetiva prestar serviços no território de abrangência para as famílias referenciadas.
Desse modo, a equipe iria até as famílias que vivem em locais de difícil acesso, distantes desta unidade física ou que estão dispersas no território.

Outro ponto considerado negativo na avaliação feita pelas famílias foi a rotatividade de profissionais, considerada um desafio a ser enfrentando em todas as políticas públicas. Em pesquisas realizadas com profissionais da área da assistência social, esse aspecto foi citado como problemático para a evolução de tal política (Leão et al. 2014; Macedo, 2007; Oliveira et al., 2011; Teixeira, 2010). O vínculo existente entre profissional e família é um fator importante para o sucesso do trabalho. No entanto, as famílias entrevistadas relatam que já passaram muitos profissionais no CRAS e que, hoje em dia, nem sabem mais quais continuam: "hoje eu não conheço mais ninguém, pra dizer que eu não conheço, eu ainda sei que é a mesma cozinheira, porque ela passa aqui na porta todo dia" (Filha, Família Duarte). Faz-se interessante ressaltar a importância do vínculo profissional-beneficiário que pode ser pensado como uma das possibilidades de compreensão da situação vivenciada por ambos e desencadeante de uma relação de confiança, o que certamente vai propiciar evolução nos atendimentos.

A Tabela 2 apresenta os dados sobre o tempo de atendimento das famílias no CRAS e o número de profissionais de nível superior (psicólogos, assistentes sociais e pedagogos) que as acompanharam efetivamente.

Seis famílias foram atendidas por 14 técnicos diferentes e nenhuma passou mais de seis meses sendo acompanhada somente por um. Vale ressaltar que esses dados são somente dos técnicos de nível superior e que os profissionais de nível médio também sofrem com todas as dificuldades trabalhistas apresentadas ante-

Tabela 2

Caracterização das famílias por tempo de atendimento no CRAS e quantidade de profissionais pelos quais foram atendidos

\begin{tabular}{lcc}
\hline Família & $\begin{array}{c}\text { Tempo de } \\
\text { atendimento (anos) }\end{array}$ & $\begin{array}{c}\text { Quantidade } \\
\text { de técnicos }\end{array}$ \\
\hline Abreu & 1 & 2 \\
Bastos & 1 & 2 \\
Castro & 3 & 3 \\
Duarte & 4 & 3 \\
Esteves & 4 & 2 \\
Fagundes & 2 & 2 \\
\hline
\end{tabular}


riormente. Isso tem como consequência a descontinuidade dos atendimentos. Como os profissionais não estão assegurados por concurso público ou carteira de trabalho (CLT), o departamento de recursos humanos pode realizar contratações e demissões sem nenhum critério regulatório, o que vai refletir diretamente no trabalho com as famílias. Tal realidade destoa do proposto pela NOB-RH/SUAS (2006), que determina que toda a equipe de referência do CRAS seja composta por servidores públicos efetivos, situação que diminui a rotatividade de profissionais, assim como garante a continuidade, eficácia e efetividade dos serviços e ações ofertados, além de permitir o processo de capacitação continuada dos profissionais. A realização de concursos públicos e a garantia dos direitos trabalhistas desses profissionais devem, portanto, constituir prioridade dos órgãos gestores da assistência social nas três esferas de governo. De acordo com o CENSO SUAS-2014 (Brasil, 2015), apenas $29,9 \%$ da equipe é servidor estatuário e $6,8 \%$ dos servidores possuem carteira assinada. Os outros vínculos (servidor comissionado, temporário, terceirizado ou outros tipos) somam 63,3\%. De acordo com a NOB SUAS-RH (Brasil, 2006), recomenda-se que haja uma transição gradativa do quadro de profissionais da equipe de referência dos CRAS que atualmente se encontra, na sua maioria, sem nenhuma garantia trabalhista. Mais uma vez o que está descrito em termos legais não está sendo efetivado na prática, talvez aí esteja um dos motivos pelos quais a assistência social tenha dificuldades de se consolidar.

Ter outras oportunidades de empregos no mercado de trabalho é uma premissa que influencia diretamente a rotatividade de profissionais. Em muitos casos, os profissionais estão trabalhando na assistência social temporariamente e, quando encontram empregos que julgam melhores, que são mais valorizados, que ganham um salário mais satisfatório ou com uma melhor carga horária e possibilidade de crescimento profissional, pedem demissão, conforme se pode ler na fala abaixo:

Ela [filha] gostava muito dela [educadora social]. Quando ela saiu, minha filha sentiu muito, ela [educadora social] ia se formar em psicóloga, aí não dava mais pra ficar aqui ganhando como professora, ela foi procurar coisa melhor pra ela, ganhar mais... Estudou pra isso... Minha filha deixou de ir pras atividades, mas eu não julgo ela não, a gente tem que procurar coisa melhor pra gente né?! (Mãe, Família Castro).
A precária estrutura física foi outro aspecto negativo citado pelas famílias e por alguns autores que pesquisaram os profissionais (Fontenele, 2008; Leão et al., 2014; Oliveira et al., 2011; Teixeira, 2010). Tais autores relatam que essa situação proporciona a desmotivação para o trabalho e a consequente saída do profissional. As pesquisas afirmam que as estruturas físicas ainda são insuficientes e parcialmente inadequadas para as potencialidades das ações previstas na proteção social básica e no Programa de Atendimento Integral à Família (PAIF). Em alguns casos faltam papel, carro para as visitas domiciliares, computadores, ventiladores etc., o que repercute na não oferta de todos os serviços previstos. De forma semelhante ao que já foi relatado em pesquisas anteriores, as famílias participantes do presente estudo também deram importância à falta de estrutura como uma dificuldade no trabalho dos profissionais, fato que desmotiva os beneficiários em participarem dos serviços. É o caso, por exemplo, da filha da família Duarte que afirma que o grupo de adolescentes que existia no CRAS foi diminuindo porque:

A professora só mandava a gente assistir filme, que era tudo repetido, ou jogar de bola, não trazia nada diferente... Ela mesma disse que não podia fazer nada porque o CRAS não tinha material suficiente para todos... De bom mesmo só a merenda... Eu acho que ela nem tem culpa, apesar de ser bem novinha, ela mesmo foi desistindo e nós também! (Filha, Família Duarte).

Os resultados acima evidenciam que a dificuldade na adesão pelos usuários é mediada pelos fatores de falta de material, distância física e rotatividade dos profissionais. Tais fatores, por sua vez, tendem a afetar a efetividade do trabalho, como no caso da orientadora social que "foi desistindo" do trabalho no CRAS. Cria-se, assim, um efeito cascata, no qual a falta de condições de atendimento e trabalho dos profissionais acaba afetando negativamente o profissional e, por conseguinte, os usuários. Corroborando pesquisas anteriores, portanto, a rotatividade de profissionais e a precária estrutura física aparecem como fatores preponderantemente negativos no atendimento ofertado pelos CRAS, a despeito do que é preconizado na PNAS (Oliveira, 2004) e na Tipificação dos Serviços Socioassistenciais (Brasil, 2005/2014).

É importante salientar que, para a efetividade dos serviços, não há apenas necessidade de espaços físicos 
adequados, mas que para a execução das atividades, com metodologias bem-estruturadas, é indispensável um ambiente acolhedor e recursos materiais adequados, como prevê a Tipificação dos Serviços Socioassistenciais (2005). Nesse sentido, o complemento de condições de trabalho, recursos materiais e vínculos empregatícios mais firmes pode ser um bom caminho para disponibilizar bons serviços à população.

Entretanto, durante a construção dos dados foram verificados aspectos de positividade e de alegria no relato dos participantes quando se referiam ao CRAS. Durante as visitas domiciliares às famílias, estas falavam do CRAS com contentamento, em especial da equipe. Apesar de criticarem a rotatividade dos profissionais, falaram com carinho das(os) técnicas(os) e educadoras(os) e da importância que tiveram em suas vidas. Mesmo que esses profissionais não estivessem mais trabalhando no CRAS, as famílias guardavam recordações boas dos encontros.

\section{Considerações Finais}

O objetivo desse artigo foi compreender a avaliação de famílias em situação de vulnerabilidade social acerca do atendimento recebido no CRAS. Os resultados mostraram que os principais fatores positivos foram: a relação família-equipe, as atividades disponibilizadas para as crianças e adolescentes e o CRAS como instituição social considerada importante para a comunidade. Como aspectos negativos do atendimento foram citados: a distância entre as casas das famílias e o CRAS, a rotatividade de profissionais e a precária estrutura física.

Visando a preencher a lacuna presente na literatura, esse artigo também busca contribuir para uma reflexão e evolução da política de assistência social, ao focalizar a ótica das famílias acerca do atendimento que recebem no CRAS. Os resultados reforçam estudos anteriores acerca da perspectiva dos psicólogos, pois muitos dos aspectos negativos descritos pelos profissionais são elencados pelas famílias participantes dessa pesquisa, ressaltando que as fragilidades da referida política já são conhecidas e que gestores precisam estar mais atentos para esses aspectos.

A metodologia de inserção ecológica demonstrou ser um método adequado para avaliação das interações estabelecidas na tríade famílias-CRAS-pesquisadora e acarretou em uma nova maneira de olhar o contexto em que a família está inserida, ou seja, não apenas investigar as características individuais, mas também as características do ambiente e as relações estabelecidas.
Os dados também dão visibilidade a aspectos que muitas vezes no cotidiano dos serviços passam despercebidos, como a importância da vinculação entre técnico-beneficiário, a escuta empática e acolhedora nos atendimentos e a prática do princípio da matricialidade sociofamiliar. Dessa forma, pode-se inferir que os profissionais dessa política, em especial os psicólogos, devem se aproximar cada vez mais dos beneficiários e compreender as contingências sociais que as levam a procurar (ou não) e aderir (ou não) aos serviços, além de frisar o olhar tanto para suas vulnerabilidades quanto para as potencialidades. Outro ponto que é comum na literatura e que se apresentou nos resultados foi a grande rotatividade de profissionais, ocasionada por fatores já conhecidos e que, de certa forma, não estão sendo contemplados pelos gestores sociais, como a escassez de concurso público e precariedade de estrutura física. Tal fato leva a pensar sobre a necessidade de uma maior articulação dos trabalhadores da assistência social em prol da luta por melhores condições de trabalho, o que irá reverberar em um melhor atendimento às famílias atendidas.

Escutar as famílias e as demandas do campo da Assistência Social é desafiante, sobretudo por se tratar de um campo relativamente recente de atuação para os psicólogos. Por isso, a pesquisa que deu origem a esse artigo foi uma grande oportunidade de ouvir as famílias atendidas pelo CRAS, compreendendo a sua avaliação sobre $o$ atendimento que recebem nesse equipamento.

Em termos de sugestões de estudos futuros, recomenda-se a realização de pesquisas que utilizem outras técnicas de coleta de dados, como o grupo focal, para se investigar a percepção de famílias atendidas no CRAS. Além disso, sugere-se a realização de pesquisas de levantamento com maior número de famílias, a fim de se verificar se a avaliação positiva feita pelos participantes desse estudo é corroborada. Estudos quantitativos desse tipo podem se mostrar interessantes por permitir o cruzamento de características sociodemográficas das famílias, motivo da busca de ajuda no CRAS e tipo de atendimento recebido com a avaliação feita pelas mesmas.

Uma vez que a PNAS (Brasil, 2004) completou dez anos em 2014, podemos considerá-la uma política "em construção", pois muitos avanços foram alcançados, mas há ainda muitos desafios a superar. Esse trabalho, ao focar a perspectiva dos usuários buscou oferecer a sua parcela de contribuição ao complexo e contínuo desafio de construção da PNAS, de forma que 
se alinhe cada vez mais às demandas e perspectivas das famílias atendidas, assim como à perspectiva da garantia de direitos que a fundamenta. A valorização da pers- pectiva dos usuários certamente constitui-se em um aspecto indispensável nesse processo, seja no âmbito de pesquisas quanto no nível de atuação.

\section{Referências}

Afonso, M. L. M., Hennon, C. B., Carico, T. L., \& Peterson, G. W. (2013). A methodological approach for working with families in SUAS: a critical reading through the lens of citizenship. Psicologia \& Sociedade, 25 (n spe.), 80-90. http://dx.doi.org/10.1590/S0102-71822013000500010

Amoretti, J., Cruz, L. R., \& Freitas, M. F. Q. (2010). Breve história e alguns desafios da psicologia social Comunitária. In J.C. Sarriera \& E.T. Saforcada (Eds.), Introdução à Psicologia Comunitária: bases teóricas e metodológicas (pp.76-96). Porto Alegre, RS: Sulina.

Andrade, L. F. \& Romagnolis, R. C. (2010). O Psicólogo no CRAS: uma cartografia dos territórios subjetivos. Psicologia: Ciência e Profissão, 30(3), 604-619. https://doi.org/10.1590/S1414-98932010000300012

Antunes, R. (2005). O caracol e sua concha: ensaios sobre a nova morfologia do trabalho. São Paulo, SP: Boitempo.

Bardin, L. (1979). Análise de conteúdo (L. A. Reto, \& A. Pinheiro, trad.). São Paulo, SP: Edições 70.

Bastos, A. V. B., Gondim, S. M. G., \& Borges-Andrade, J. E. (2010). O psicólogo brasileiro: sua atuação e formação profissional: o que mudou nessa última década? In O. H. Yamamoto, \& A. L. F. Costa (Eds.), Escritos sobre a profissão de psicólogo no Brasil (pp. 257-271). Natal, RN: EDUFRN.

Barros, J. P. P. (2007). Considerações sobre a práxis do(a) psicólogo nas Raízes de Cidadania e nos Centros de Referência de Assistência Social (CRAS) de Fortaleza (monografia). Universidade Federal do Ceará, Fortaleza, CE.

Benevides, R. (2005). A psicologia e o Sistema Único de Saúde. Psicologia e Sociedade, 17(2), 21-25. https://doi.org/10.1590/S0102-71822005000200004

Bock, A. M. B. (2003). Psicologia e sua ideologia: 40 anos de compromisso com as elites. In A. M. B. Bock (Ed.), Psicologia e o compromisso social (pp. 15-28). São Paulo, SP: Cortez.

Brasil. (2005). Ministério do Desenvolvimento Social. Norma operacional básica. Brasília, DF: o autor.

Brasil. (2006). Ministério do Desenvolvimento Social. Sistema Único de Assistência Social - SUAS. Norma operacional básica de recursos humanos do SUAS - NOB-RH/ SUAS. Brasília, DF: o autor.

Brasil. (2015). Ministério do Desenvolvimento Social e Combate à Fome. Censo SUAS 2014. Brasília, DF: o autor.

Brasil (2004). Ministério do Desenvolvimento Social e Combate à Fome. Política Nacional de Assistência Social. Brasília, DF: o autor.

Brasil. (2014). Ministério do Desenvolvimento Social e Combate à Fome. Tipificação nacional de serviços socioassistenciais. Brasília, DF: o autor. (Originalmente publicado em 2005).

Bronfenbrenner, U. (1995). Bioecological model form a life course perspective: Reflections of a participant observer. In P. M. Moen, G. H. Elder \& K. Lüscher (Eds.), Examining lives in context: perspectives on the ecology of human development (pp. 599-618). Washington, DC: American Psychological Association.

Bronfenbrenner, U. (1989). Ecological systems theory. Annals of Child Development, (6), 187-249.

Cecconello, A. M. \& Koller, S. H. (2003). Inserção ecológica na comunidade: uma proposta metodológica para o estudo de famílias em situação de risco. Psicologia: Reflexão e Crítica,16(3), 515-524. https://doi.org/10.1590/S0102-79722003000300010

Centro de Referência Técnica em Psicologia e Políticas Públicas - CREPOP. (2007). Referência técnica para atuação do(a) psicólogo(a) no CRAS/SUAS. Brasília, DF: Conselho Federal de Psicologia.

Freitas, M. F.Q. (1998). Inserção na comunidade e análise de necessidades: reflexões sobre a prática do psicólogo. Psicologia: Reflexão e Crítica, 11(1), 175-189. https://doi.org/10.1590/S0102-79721998000100011

Fontenele, A. F. G. T. (2008). Psicologia e Sistema Único da Assistência Social - SUAS: estudo sobre a atuação dos psicólogos nos Centros de Referência da Assistência Social - CRAS (dissertação de mestrado). Universidade Federal do Ceará, Fortaleza, CE. 
Guerra, A. M. C. (2002). O social na clínica e a clínica do social: sutilezas de uma prática. In B. D. Gonçalves, A. M. C. Guerra \& J. O. Moreira (Eds.), Clínica e inclusão social: novos arranjos subjetivos e novas formas de intervenção (pp. 29-48). Belo Horizonte, MG: Campo Social.

Leão, S. M., Oliveira, I. M. F. F., \& Carvalho, D. B. (2014). O Psicólogo no campo do bem-estar social: atuação junto às famílias e indivíduos em situação de vulnerabilidade e risco social no Centro de Referência de Assistência Social (CRAS). Estudos e Pesquisas em Psicologia, 14(1), 264-289. Recuperado de http:// pepsic.bvsalud.org/scielo. php?script=sci_arttext\&pid=S1808-42812014000100015

Macedo, J. P. S. (2007). O psicólogo no campo do bem-estar: cartografias de práticas na saúde e assistência social (dissertação de mestrado), Universidade Federal do Rio Grande do Norte, Natal, RN.

Macedo. J. P., \& Dimenstein, M.(2012). O trabalho dos psicólogos nas políticas sociais no Brasil. Avances en Psicología Latinoamericana, 30(1), 182-192. Recuperado de http://www.scielo.org.co/pdf/apl/v30nl/v30nla15.pdf

Macedo, J. P., Sousa, A. P., Carvalho, D. M., Magalhães, M. A., Sousa, F. M. S., \& Dimenstein, M. (2011). O psicólogo brasileiro no SUAS: quantos somos e onde estamos? Psicologia em Estudo, 16(3), 479-489. https://doi.org/10.1590/S1413-73722011000300015

Morais, N. A., Koller, S. H., \& Raffaelli, M. (2016). Inserção ecológica na pesquisa sobre trajetórias de vida de adolescentes em situação de vulnerabilidade social: identificando fatores de risco e proteção. In S. H. Koller, N. A. Morais, \& S. S. Paludo (Orgs.), Inserção ecológica: um método de estudo do desenvolvimento humano (pp. 65-91). São Paulo, SP: Casa do Psicólogo.

Nepomuceno, L. B., Ximenes, V. M., Cidade, E. C., Mendonça, F. W. O., \& Soares, C. A. (2008). Por uma psicologia comunitária como práxis de libertação. Psico, 39(4), 456-464. Recuperado de http://revistaseletronicas.pucrs.br/ ojs/index.php/revistapsico/article/view/3532

Oliveira, I. F., Dantas, C. M. B., Solon, A. F. A. C., \& Amorim, K. M. O. (2011). A prática psicológica na proteção social básica do SUAS. Psicologia \& Sociedade, 23(n esp),140-149. https://doi.org/10.1590/S0102-71822011000400017

Paula, L. R. C.(2010). As significações do programa bolsa família: um estudo com mulheres acompanhadas por centros de Referência da Assistência Social em Fortaleza, 2010 (dissertação de mestrado). Universidade Federal do Ceará, Fortaleza, CE.

Perez, R. (2009). Um estudo sobre a não participação de mulheres em situação de pobreza em cursos oferecidos por um CRAS (dissertação de mestrado). Universidade de São Paulo, São Paulo, SP.

Prati,L.E.,Couto,M.C.P.P., Moura,A.,Poletto.M., \&Koller,S.H.(2008). Revisandoainserçãoecológica:umapropostade sistematização. Psicologia: Reflexão e Crítica, 21(1), 160-169. https://doi.org/10.1590/S0102-79722008000100020

Raichelis, R. (2010). Intervenção profissional do assistente social e as condições de trabalho no SUAS. Serviço Social \& Sociedade, (104), 750-772. http:// dx.doi.org/10.1590/S0101-66282010000400010

Santos, T. F. S. (2010). O trabalho com famílias nos CRAS e CREAS de São Paulo: a matricialidade sociofamiliar tem centralidade? (Trabalho de conclusão de curso). Universidade Cruzeiro do Sul, São Paulo, SP.

Seixas, P.S (2009). Inserção e atuação profissional do psicólogo no campo das políticas públicas no Rio Grande do Norte (dissertação de mestrado). Universidade Federal do Rio Grande do Norte, Natal, RN.

Senra, C. M. G. (2009). Psicólogos sociais em instituição pública de Assistência Social:analisando estratégias de enfrentamento (tese de doutorado). Pontifícia Universidade Católica de Campinas, Campinas, SP

Senra, C.M. G., \&Guzzo, R. S. L. (2012). Assistência social e psicologia: sobre as tensões e conflitos do psicólogo no cotidianodoserviçopúblico. Psicologia\&Sociedade,24(2),293-299.https://doi.org/10.1590/S0102-71822012000200006

Silva, J. V. \& Corgozinho, J. P. (2011). Atuação do psicólogo, SUAS/CRAS e psicologia social comunitária: possíveis articulações. Psicologia \& Sociedade; 23(n spe.), 12-21. https://doi.org/10.1590/S0102-71822011000400003

Sposati, A. (2009). Horizontes da e para a política de assistência social no Brasil de 2009: elementos para a discussão. In: Políticas públicas em debate: ciclo de seminários (pp.1-19). São Paulo: Fundap.

Tavares, G. M. (2014). Sobre olhares e práticas psicológicas na assistência social. Psicologia em Estudo, 19(3), p. 449-457. https://doi.org/10.1590/1413-73722217208

Teixeira, S. M. (2010). Trabalho Interdisciplinar nos CRAS: um novo enfoque e trato à pobreza? Textos \& Contextos, 9(2), 286- 297. Recuperado de http://revistaseletronicas.pucrs.br/ojs/index.php/fass/article/view/7032 
Ximenes, V. M., Paula, L. R. C., \& Barros, J. P. P. (2009). Psicologia comunitária e política de assistência social: diálogos sobre atuações em comunidades. Psicologia Ciência e Profissão, 29(4), 686-699. https:// doi.org/10.1590/S1414-98932009000400004

Yamamoto, O. H. (2007). Políticas sociais, "terceiro setor" e "compromisso social": perspectivas e limites do trabalho do psicólogo. Psicologia \& Sociedade, 19(1), 30-37. httpS:// doi.org/10.1590/S0102-71822007000100005

Yamamoto, O. H. (2003). Questão social e políticas públicas: revendo o compromisso da Psicologia. In: A.M.B.Bock (Ed.). Psicologia e compromisso social (pp. 37-54). São Paulo, SP: Cortez.

Yamamoto. O. H., \& Oliveira, I. F. (2010). Política social e Psicologia: uma trajetória de 25 anos. Psicologia: Teoria e Pesquisa, 26( n esp.), 9-24. https://doi.org/10.1590/S0102-37722010000500002

\section{Anne Graça de Sousa Andrade}

Mestre em Psicologia pela Universidade de Fortaleza. Docente da Universidade Estadual do Ceará. Faculdade Luciano Feijão.

E-mail: annegsa@hotmail.com

\section{Normanda Araujo de Morais}

Doutora em Psicologia pela Universidade Federal do Rio Grande do Sul (UFRGS). Professora Titular do Programa de Pós-Graduação em Psicologia da Universidade de Fortaleza.

E-mail: normandaaraujo@gmail.com

Endereço para envio de correspondência:

Universidade de Fortaleza, Programa de Pós-Graduação em Psicologia.

Av. Washington Soares, 1321, Bloco N - Sala 13, Edson Queiroz.

Fortaleza - CE, Brasil.

CEP: 60811-905

Recebido 18/04/2016

Reformulação 03/10/2016

Aprovado 13/02/2017

Received 04/18/2016

Reformulated $10 / 03 / 2016$

Approved 02/13/2017

Recebido 18/042016

Reformulado 03/10/2016

Aceptado 13/02/2017

Esse artigo é resultado da dissertação intitulada "Família e Centro de Referência de Assistência Social (CRAS):

avaliação do atendimento recebido", desenvolvida pela primeira autora, sob orientação da segunda, no Programa de Pós-graduação em Psicologia da Universidade de Fortaleza. 
Como citar: Andrade, A G. S., \& Morais, N. A. (2017). Avaliação do atendimento recebido no CRAS por famílias usuárias. Psicologia: Ciência e Profissão, 37(2), 378-392. https://doi.org/10.1590/1982-370301412016

How to cite: Andrade, A G. S., \& Morais, N. A. (2017). Assessment, by user families, of the service received in the CRAS. Psicologia: Ciência e Profissão, 37(2), 378-392. https://doi.org/10.1590/1982-370301412016

Cómo citar: Andrade, A G. S., \& Morais, N. A. (2017). Evaluación de la atención recibida en el CRAS por familias usuarias. Psicologia: Ciência e Profissão, 37(2), 378-392. https://doi.org/10.1590/1982-370301412016 